\title{
Added Value of Foot X-Ray to the Clinical Foot Postural Index in Patients with Early and Late Rheumatoid Arthritis: A Comparative Study
}

\author{
HATEM AHMED, M.Sc. ${ }^{\mathbf{~}}$; MOHAMED KAMAL, M.D. ${ }^{\mathbf{1 , 2}}$; MOUSTAFA E. RADWAN, M.D. ${ }^{\mathbf{3 , 4}}$ and \\ ABD EL-MAGEED EL-ASHMAWY, M.D. ${ }^{1}$
}

The Department of Rheumatology, Faculty of Medicine, Al-Azhar University, Egypt ${ }^{1}$, The Department of Internal Medicine, Faculty of Medicine, Taibah University, $\mathrm{KSA}^{2}$, The Department of Radiodiagnosis, Faculty of Medicine, Taibah University, $K S A$ and Faculty of Medicine, Assiut University, Egypt ${ }^{4}$

\begin{abstract}
Background: FPI-6 is considered a quick and simple clinical test in patients with Rheumatoid Arthritis (RA). However, its associations with different clinical and radiological parameters of the disease are not fully studied.

Aim of Study: To assess the added value of foot radiology to the Foot Postural Index-6 (FPI-6) in assessment of early and late rheumatoid arthritis.

Patients and Methods: The subjects were recruited over a period of 6 months from the Rheumatology outpatient's clinics in Al-Azhar University Hospitals, Egypt. FPI-6 was calculated in 90 subjects, 30 patients with early RA (disease duration $^{<5}$ years), 30 patients with late RA (disease duration $>5$ years) and 30 age and gender matched control subjects. Foot digital X-rays in the standing position were performed to measure foot angles; TNC (Talonavicular Coverage), first metatarsal talar (1 st MT) and Calcaneal Pitch (CP) angles.

Results: Pesplanus valgus was detected in $20 \%$ of early and $80 \%$ of late RA patients. Patients with late RA showed significantly higher bilateral FPI- 6 than both the control subjects and patients with early RA $(p=0.001)$. They also had significantly higher TNC, and 1st MT and lower CP $(p=0.001)$. In RA patients, FPI- 6 correlated significantly with both the duration of RA and the foot radiographic changes.

Conclusions: The combined use of FPI-6 with radiological measurements of three angles of plain X-ray in addition to, the collapse of the longitudinal arch; Talonavicular Coverage angle (TNC); Lateral talar-1 st metatarsal angle and Calcaneal pitch can be used in the clinical assessment of forefoot abduction and the severity of RA.
\end{abstract}

Key Words: Rheumatoid arthritis - Foot posture index - FPI6 - Talonavicular coverage - First metatarsal talar-Calcaneal pitch.

Correspondence to: Dr. Moustafa E. Radwan, E-Mail: ezeldienmos@yahoo.com

\section{Introduction}

RHEUMATOID Arthritis (RA) is a chronic, multisystem disease that characterized by synovial inflammation and proliferation, loss of cartilage and erosion of the juxta-articular bone [1] . Inflammation of the small joints of the hands and feet represents the indication of early RA [2,3]. Clinical practice guidelines strongly recommend to look for metatarsal pain and/or foot alignment biomechanical faults in patients with early RA [4]. Some studies have shown that simple X-ray of feet may provide an earlier and more frequent joint damage than the radiology of hands $[\mathbf{5 , 6}]$. Concerning the articular damage of feet in RA, the considerable weight bearing mechanical stress adds to the damage from chronic synovitis and may result in characteristic irreversible structural changes [7]. This could be observed in the subtalar and talonavicular joints with flattening of the medial longitudinal arch, valgus deformity of the calcaneus and tibialis posterior dysfunction $[\mathbf{1 , 8}]$. Abnormal foot posture, such as enormous pronation and supination, has been identified as a causative factor in the dysfunction of feet and the lower extremities [9].

Moreover, the affection of the ankle joint may lead to decreased dorsal flexion which could interfere with walking ability [10] . FPI-6 is considered as a quick, easy and reliable clinical method for measuring foot position that yields high quality linear metric data [11]. It has been clinically applied in a variety of clinical settings including RA [12]

The aim of the current study was to compare FPI-6 and foot radiology in normal, early and advanced RA patients. 


\section{Subjects and Methods}

This current study was carried out over a period of 6 months, in the Rheumatology Outpatient's Clinics in Al-Azhar University Hospitals, Egypt. Ninety subjects were selected and divided into three groups; Group A: 30 patients with rheumatoid arthritis of fewer than five years duration, Group B: 30 patients with rheumatoid arthritis of more than five years duration, and Group C: 30 age and gender matched control subjects who have no rheumatoid arthritis.

Inclusion criteria: The patients chosen were fulfilling the 2010 American College of Rheumatology/European League Against Rheumatism classification criteria for Rheumatoid arthritis.

Exclusion criteria: Patients suffered from Diabetes mellitus, those who have associated rheumatic disorders (gout, primary generalized erosive OA, etc.), patients with previous ankle trauma and congenital malformations.

\section{Methods:}

1- All the subjects had full medical history recorded, complete general and Rheumatological clinical examination.

2- Laboratory investigations for all subjects included complete blood count: Done by coulter method using (Cell Dyne 1700 instrument), erythrocyte sedimentation rate (Westergren method), blood sugar, serum uric acid by using, urine analysis, C-Reactive protein, and Rheumatoid factor.

3- All the included individuals had their FPI-6 measured, which consists of 6 clinical parameters; (1) Talar head palpation, (2) Supra and infra lateral malleolar curvature, (3) Calcaneal frontal plane position, (4) Prominence in the region of the talonavicular joint, (5) Congruence of the medial longitudinal arch, and (6) Abduction or adduction of the forefoot in the rear foot.

4- Digital X-rays: All the included individuals had digital X-rays of both feet in standing position in lateral and anteroposterior views, where three angles were measured on each of the X-ray films to assess the forefoot abduction in addition to the collapse of the longitudinal arch. All films are interpreted blindly by an expert radiologist. Pesplanus Valgus (PPV) was considered to be present if there was an increase in the value of FPI-6, TNC angle, ${ }^{1 \text { st }}$ MT and/or a decrease of the $\mathrm{CP}$ angle of plain X-ray in standing position.
Forefoot abduction was assessed by Talonavicular Coverage Angle (TNC):

A weight-bearing AP view is used to measure the Talonavicular Coverage Angle (TNC); an angle of larger than 7 degrees specifies lateral talar subluxation.

Collapse of the medial longitudinal arch is assessed by two angles:

A- Lateral talar-1st metatarsal angle: A weightbearing lateral view is used to measure the Lateral talar- 1 st metatarsal angle which is formed between the long axis of the talus and first metatarsal. In the normal weight-bearing foot, the midline axis of the talus is in line with the midline axis of the first metatarsal. An angle that is greater than $4^{\circ}$ convex downward is considered pes planus with an angle of $15^{\circ}-30^{\circ}$ considered moderate, and greater than $30^{\circ} \mathrm{se}-$ vere. An angle greater than 4 degrees convex upward is considered a pes cavus.

$B$ - Calcaneal pitch: A weight-bearing lateral view is used to measure the calcaneal pitch, a decreased calcaneal pitch is consistent with pes planus.

Ethical considerations: A formal consent was taken from every subject in the study, and the protocol was approved from the local ethical committee.

\section{Statistical analysis:}

Descriptive statistical analysis was done with IBM SPSS Statistics software release 21; SPSS Inc. for Windows (Microsoft).

\section{Results}

This current research was conducted on 90 subjects that was divided into three groups; Group A: 30 patients with rheumatoid arthritis of fewer than five years duration, Group B: 30 patients with rheumatoid arthritis of more than five years duration, and Group C: 30 age and gender matched control subjects who have no rheumatoid arthritis.

There was a high significant difference between groups in gender, age, and duration of illness. Group B was older and had a longer duration of disease than group A with no significant difference in age between group A and group C (Table 1).

Thirty rheumatoid patients of a duration of fewer than five years (Group A) underwent Foot Posture Index (FPI-6).

Six out of the thirty RA patients who have disease duration fewer than five years (group A) 
showed an increase in the value of FPI- 6 of right and left foot. The increase of FPI- 6 in these 6 patients denotes the presence of Pes Planus Valgus (PPV). The presence of right and left PPV of these 6 patients is also supported by the radiological studies reported in the present work, which showed an increase of the talonavicular and first metatarsal angles with decreased of the calcaneal pitch angle Figs. (1-3). On both sides, FPI-6 was positively correlated with age, duration, TNC and first metatarsal angle and was negatively correlated to $\mathrm{CP}$.

Twenty-four out of the thirty RA patients who have disease duration greater than five years (group B) showed increased FPI-6 of right and left foot, indicating the occurrence of pes planus valgus. The presence of right and left PPV in these 24 studied rheumatoid patients was supported by the radiological findings which showed increased talonavicular and first metatarsal angles and decreased calcaneal pitch Figs. (1-3). On both sides, FPI-6 was positively correlated with age, duration, TNC and 1 st metatarsal angle and was negatively correlated to $\mathrm{CP}$.

Patients with late RA showed significantly higher bilateral FPI- 6 than both patients with early RA and the control subjects $(p=0.001)$ (Table 2$)$.

Early RA patients showed significantly higher bilateral TNC than the control subjects $(p=0.001)$, while patients with late RA showed significantly higher bilateral TNC and 1 st MT than both the patients with early RA and the control subjects ( $p=$ 0.001). Also, they showed significantly lower bilateral CP than both the patients with early RA and the control subjects $(p=0.001)$ (Table 3$)$.

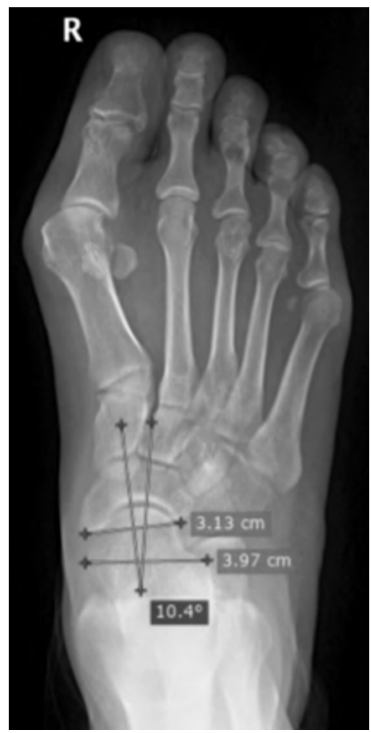

Fig. (1): Plain X-ray AP view of the Rt. foot standing position showed increased talonavicular coverage angle (10.40) that indicates lateral talar subluxation.

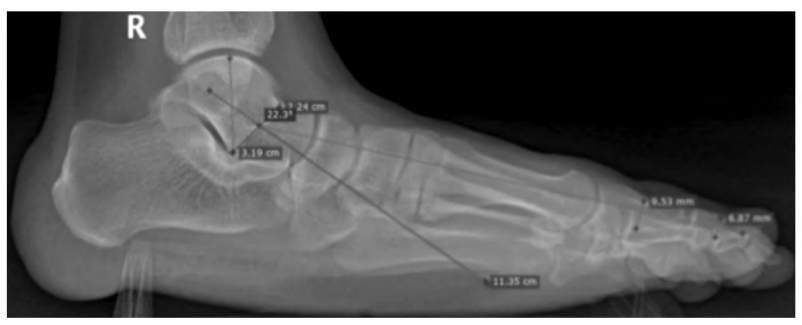

Fig. (2): Plain X-ray lateral View RT foot showed lateral talar1 st metatarsal angle measuring (22.30) that is considered moderate pes planus.

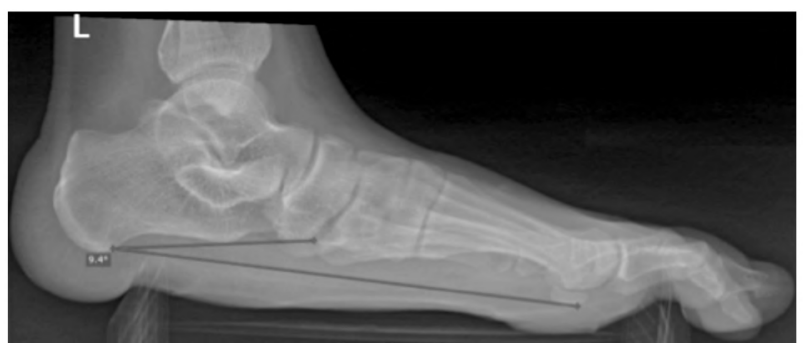

Fig. (3): Plain X-ray left foot lateral view showed a decreased calcaneal pitch (9.40) that is consistent with pes planus.

Table (1): Distribution of cases in the study groups in relation to sex, age and duration of illness.

\begin{tabular}{lllll}
\hline Variables & \multicolumn{1}{c}{$\begin{array}{c}\text { Group } \\
\text { A }\end{array}$} & \multicolumn{1}{c}{$\begin{array}{c}\text { Group } \\
\text { B }\end{array}$} & \multicolumn{1}{c}{ Group } & $\begin{array}{c}p \\
\text { C- } \\
\text { value }\end{array}$ \\
\hline Males & $7 / 30(23.3 \%)$ & $11 / 30(36.7 \%)$ & $22 / 30(73.3 \%)$ & 0.001 \\
Females & $23 / 30(76.7 \%)$ & $19 / 30(63.3 \%)$ & $8 / 30(26.7 \%)$ & 0.001 \\
Age/year & $35.9 \pm 10.68$ & $47.4 \pm 9.57$ & $39.6 \pm 8.69$ & 0.001 \\
Duration/year & $1.49 \pm 0.47$ & $12.5 \pm 5.57$ & & \\
\hline
\end{tabular}

Table (2): The right and left FPI-6 in early and late RA patients in comparison to control subjects.

\begin{tabular}{lcccr}
\hline & Group A & Group B & Group C & $p$-value \\
\hline Rt. foot & $1.07 \pm 1.01$ & $6.10 \pm 2.59$ & $1.63 \pm 2.16$ & 0.001 \\
Lt. foot & $1.73 \pm 1.51$ & $7.30 \pm 3.31$ & $1.43 \pm 2.22$ & 0.001 \\
\hline
\end{tabular}

Table (3): The foot radiology in early and late RA patients in comparison to control subjects.

\begin{tabular}{lllll}
\hline & Group A & Group B & Group C & $p$ \\
\hline$T N C:$ & & & & \\
Rt. side & $6.47 \pm 2.27$ & $9.80 \pm 4.70$ & $4.03 \pm 5.51$ & 0.001 \\
Lt. side & $7.10 \pm 1.73$ & $10 \pm 3.18$ & $4.63 \pm 5.24$ & 0.001 \\
1st $M T:$ & & & & \\
Rt. side & $4.80 \pm 2.87$ & $13.2 \pm 6.49$ & $3.80 \pm 3.97$ & 0.001 \\
Rt. side & $4.93 \pm 2.50$ & $12.1 \pm 5.11$ & $3.07 \pm 4.23$ & 0.001 \\
CP: & & & & \\
Rt. side & $18.33 \pm 1.95$ & $14.2 \pm 3.60$ & $18.37 \pm 1.87$ & 0.001 \\
Lt. side & $17.77 \pm 3.41$ & $14.1 \pm 3.84$ & $18.73 \pm 2.07$ & 0.001 \\
\hline
\end{tabular}

\section{Discussion}

Rheumatoid Arthritis (RA) is a long-lasting autoimmune disorder that chiefly affecting the joints. Most frequently, symmetrical bilateral af- 
fection of the wrist and hands are noted in RA patients.

RA affects between 0.5 and $1 \%$ of adults in the developed countries with between 5 and 50 per 100,000 people newly developing the disease each year. Onset is most common in the middle age, and women are affected 2.5 times more than the men [13-15].

Small joint inflammation is an indication of early RA, however estimating the affection of the foot and ankle has been usually underestimated. Usually the clinician find it simpler to look at the hands in an examination rather than the feet and therefore there appears to be a lack of attention paid to this problem [16]

The Foot Posture Index (FBI-6) is an emerging clinical index that was used in this study. It is considered a quick, easy and dependable footspecific outcome measure for assessing foot position in a variety of clinical settings [12] ; it is also suitable for a range of clinical applications [11].

The current study showed that there was no significant difference in the values of FPI-6 between normal males and females. This is in agreement with that reported by Redmond et al., 2008 [17]

In this study, the higher values of FPI-6 and higher prevalence of foot deformity in late RA patients (Group B) rather than in early cases (Group A) signified the impact of the disease duration on the foot health; these results are in agreement with other previous studies [18,19]. Spiegel et al., 1982 study reported a prevalence of $46 \%$ of 'flat feet' in their cohort [19].

To our knowledge; no previous studies combine the FPI-6 with radiological measurements of three angles of plain X-ray to assess the forefoot abduction, in addition to, the collapse of the longitudinal arch; Talonavicular Coverage Angle (TNC); lateral talar-1 st metatarsal angle and Calcaneal pitch in patients with early and late rheumatoid arthritis in comparison to normal individuals, as previous studies relied upon only FPI-6 in assessment of forefoot abduction.

The radiological findings including the increase in both the Talonavicular Coverage Angle (TNC) and lateral talar- 1 st metatarsal angle with decrease in the calcaneal pitch used in this current study supported the increased FPI-6 in diagnosis of Pes Planus Valgus (PPV); 6/30 in early RA patients (Group A) and 24/30 in late RA patients (Group B) and this is very important as the use of radio- logical measurements removes the influence that the soft tissue structures may have on measurements. In one study by Shi et al., 2000 they used only the $\mathrm{CP}$ angle in assessing the diagnosis of Pes Planus Valgus (PPV), as they performed serial radiographs of the feet in a cohort of patients with RA and found an increasing prevalence of flat foot as measured by the calcaneal pitch, the deformity being worse in a group with more severe disease [18].

\section{Conclusions:}

The combined use of FPI- 6 with radiological measurements of three angles of plain X-ray in addition to, the collapse of the longitudinal arch; Talonavicular Coverage Angle (TNC); lateral talar$1{ }^{\mathrm{st}}$ metatarsal angle and calcaneal pitch can be used in the clinical assessment of forefoot abduction and the severity of RA.

Conflict of interest: The authors have not any conflict of interest to declare.

\section{References}

1- McGONAGLE D., et al.: Imaging the joints in early rheumatoid arthritis. Best Pract. Res. Clin. Rheumatol., 15 (1): p. 91-104, 2001.

2- ALETAHA D., et al.: Rheumatoid arthritis classification criteria: An American College of Rheumatology/European League Against Rheumatism collaborative initiative. Ann. Rheum. Dis., 69 (9): p. 1580-8, 2010.

3- JAMES R. O'DELL, JOHN B. IMBODEN and L.D. MILLER: Rheumatoid arthritis in Current Diagnosis and Treatment Rheumatology, D.B.H.a.J.H.S. John B. Imboden, Editor, McGraw Hill Medical: USA, p. 139-55, 2013.

4- KORDA J. and G.P. BALINT: When to consult the podiatrist. Best Pract. Res. Clin. Rheumatol., 18 (4): p. 587 $611,2004$.

5- HULSMANS H.M., et al.: The course of radiologic damage during the first six years of rheumatoid arthritis. Arthritis Rheum, 43 (9): p. 1927-40, 2000.

6- OSTENDORF B., et al.: Diagnostic value of magnetic resonance imaging of the forefeet in early rheumatoid arthritis when findings on imaging of the metacarpophalangeal joints of the hands remain normal. Arthritis Rheum, 50 (7): p. 2094-102, 2004.

7- GOSSEC L., et al.: Nonpharmacological treatments in early rheumatoid arthritis: Clinical practice guidelines based on published evidence and expert opinion. Joint Bone Spine, 73 (4): p. 396-402, 2006.

8- RICHIE D.H., Jr.: Biomechanics and clinical analysis of the adult acquired flatfoot. Clin. Podiatr. Med. Surg., 24 (4): p. 617-44, VII, 2007.

9- ALLEN M.K. and W.M. GLASOE: Metrecom measurement of navicular drop in subjects with anterior cruciate ligament injury. J. Athl. Train., 35 (4): p. 403-6, 2000. 
10- KAO P.C. and D.P. FERRIS: Motor adaptation during dorsiflexion-assisted walking with a powered orthosis. Gait Posture, 29 (2): p. 230-6, 2009.

11- KEENAN A.M., et al.: The Foot Posture Index: Rasch analysis of a novel, foot-specific outcome measure. Arch. Phys. Med. Rehabil., 88 (1): p. 88-93, 2007.

12- REDMOND A.C., J. CROSBIE and R.A. OUVRIER Development and validation of a novel rating system for scoring standing foot posture: The Foot Posture Index. Clin Biomech (Bristol, Avon), 21 (1): p. 89-98, 2006.

13- JI J.D., et al.: Association of STAT4 polymorphism with rheumatoid arthritis and systemic lupus erythematosus: A meta-analysis. Mol. Biol. Rep., 37 (1): p. 141-7, 2010.

14- TURESSON C., et al.: Extra-articular disease manifestations in rheumatoid arthritis: Incidence trends and risk factors over 46 years. Ann. Rheum. Dis., 62 (8): p. 722 7, 2003.
15- SCOTT D.L., F. WOLFE and T.W. HUIZINGA: Rheumatoid arthritis. Lancet, 376 (9746): p. 1094-108, 2010.

16- GRONDAL L., et al.: The foot: Still the most important reason for walking incapacity in rheumatoid arthritis: Distribution of symptomatic joints in 1,000 RA patients. Acta. Orthop., 79 (2): p. 257-61, 2008

17- REDMOND A.C., Y.Z. CRANE and H.B. MENZ: Normative values for the Foot Posture Index. J. Foot Ankle Res., 1 (1): p. 6, 2008.

18- SHI K., et al.: Foot deformities in rheumatoid arthritis and relevance of disease severity. J. Rheumatol., 27 (1): p. 84-9, 2000.

19- SPIEGEL T.M. and J.S. SPIEGEL: Rheumatoid arthritis in the foot and ankle--diagnosis, pathology, and treatment. The relationship between foot and ankle deformity and disease duration in 50 patients. Foot Ankle, 2 (6): p. 31824, 1982.

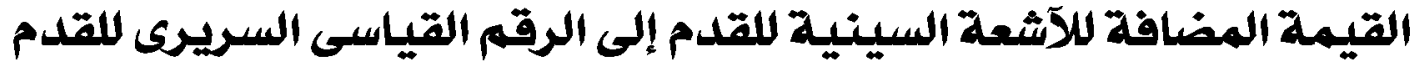

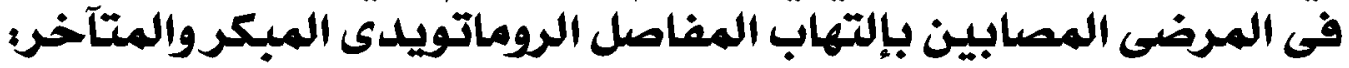 دراسة مقارنة}

\footnotetext{
الخلفية: يعتبر FPI-6 إختبار سريرى سريع وبسيط فى المرضى الذين يعانوف من إلتهاب المفاصل الروماتويدى (RA) . ومع ذلك، لم يتم

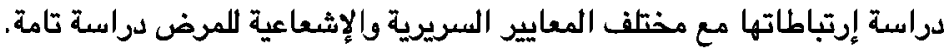

الهدف من الدراسةة: تقييم القيمة المضافة لآشعة القدم إلى مؤثر القدم 7 (FPI-6) في تقييم المرضي المصابين بإلتهاب المفاصل

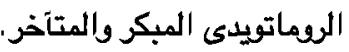

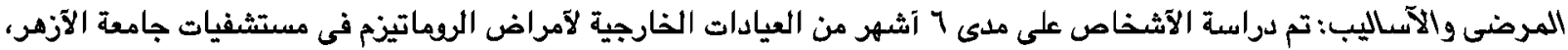

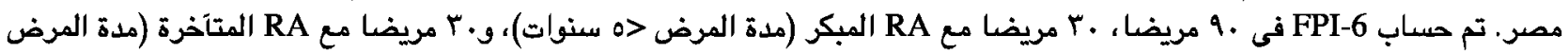

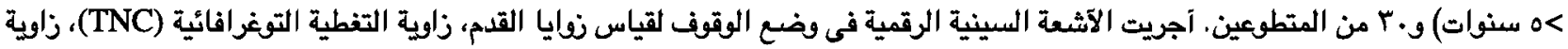

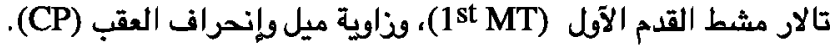

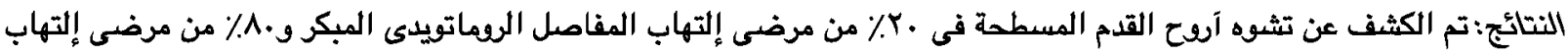

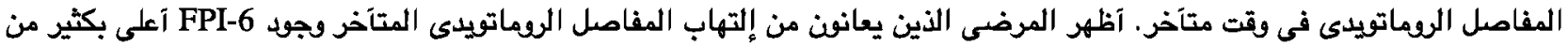

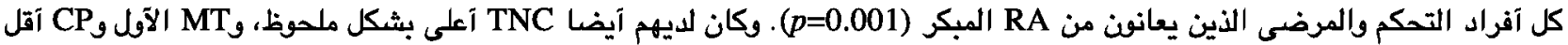
( RA ترتبط FPI-6 بشكل كبير مع كل من مدة RA والتفيرات التى تظهر بالآثعة السينية للقدم.

الإستتاجات :الإستخدام المشترك ل FPI-6 مع القياسات الإثعاعية لثلاث زفايا من الآثعة السينية للقدم يمكن أن يستخدم لتقييم شدة

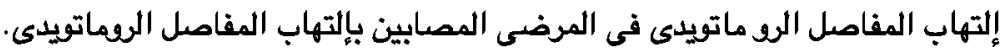

